\title{
OFERTA DE FERRO A PRÉ-ESCOLARES DE UMA REDE MUNICIPAL DE ENSINO NO EXTREMO SUL DE SANTA CATARINA
}

\section{Iron supply by preschool children enrolled on municipal system education of the South of Santa Catarina}

Abigail Lopes ${ }^{1,2}$, Luciane Bisognin Ceretta ${ }^{1,2}$, Lisiane Tuon ${ }^{1,2}$, Josete Mazon ${ }^{1}$, Ingrid Dalira Schweigert Perry ${ }^{1,2}$, Priscyla Waleska Simões ${ }^{1,2}$, Rita Suselaine Vieira Ribeiro ${ }^{1}$

${ }_{1}$ Programa de Residência Multiprofissional em Atenção Básica/Saúde da Família Universidade do Extremo Sul Catarinense - UNESC, Criciúma, SC, Brasil.

2 Programa de Pós-Graduação em Saúde Coletiva (Mestrado Profissional) Universidade do Extremo Sul Catarinense - UNESC, Criciúma, SC, Brasil

\section{Endereço para correspondência:}

\section{Rita Suselaine Vieira Ribeiro}

Programa de Residência Multiprofissional em Atenção Básica/Saúde Coletiva Universidade do Extremo Sul Catarinense, Av. Universitária, 1105. Criciúma - SC Bairro Universitário. CEP - 88806-000

Email: rsv@unesc.net 


\section{Resumo}

Introdução: A anemia ferropriva é a carência nutricional mais prevalente no mundo, e importante problema de Saúde Pública. Objetivos: Avaliar a oferta de ferro a préescolares, analisando cardápio de um centro de educação infantil de um município sul catarinense, comparando ao preconizado pelo Programa Nacional de Alimentação Escolar. Métodos: Realizou-se estudo observacional, transversal, descritivo, prospectivo, de abordagem quantitativa. Analisou-se o teor de ferro de alimentos ofertados para pré-escolares de 1 a 5 anos, durante uma semana. Resultados: Crianças de 1 a 3 anos, no período matutino, receberam quantidade de ferro superior a recomendação, adequada em $205,81 \%( \pm 27,32)$. Já no período vespertino, a oferta adequou-se em $96,67 \%( \pm 31,26)$. Na faixa etária dos 4 aos 5 anos, no matutino, atingiuse a recomendação em $144,07 \%( \pm 19,13)$; embora, no vespertino, a adequação foi $67,67 \%( \pm 21,88)$. Crianças de 1 a 3 anos e de 4 a 5 anos, no período integral, atingiram adequação de $129,63 \%( \pm 17,82)$ e $90,74 \%( \pm 12,47)$, respectivamente. Os alimentosfontes ofertados foram: feijão preto, beterraba crua, ovo, carne bovina, peito e coxa de frango. Conclusões: Conclui-se com o presente estudo que a oferta de ferro foi adequada apenas para os pré-escolares de 1 a 3 anos, no período matutino. $O$ almoço foi a refeição mais rica em ferro.

Palavras-chave: Anemia; Anemia Ferropriva; Ferro; Pré-escolar; Saúde Pública.

\section{Abstract}

Background: Iron deficiency anemia is the most common nutritional deficiency of the world and an important public health issue. Objective: Evaluating iron offered to preschoolers, analyzing the menu of an early childhood education center of the south of Santa Catarina, comparing it with Programa Nacional de Alimentação Escolar. Methods: A cross-sectional, descriptive, prospective study was conducted using a quantitative approach. Was analyzed iron content of foods offered to preschoolers 1-5 years in, during a week. Results: Children 1-3 years, in the morning, received iron higher than recommendation, adequate in $205.81 \%( \pm 27.32)$. However, in the afternoon, iron was adequate in $96.67 \%( \pm 31.26)$. Children $4-5$ years, on the morning shift, was hit the recommendation in $144.07 \%( \pm 19.13)$; although, in the afternoon, the average percentage of adequacy was $67.67 \%( \pm 21.88)$. Children receiving full power $1-3$ years and $4-5$ years, 
Artigo Original

Atenção à Saúde

averaged adequacy $129.63 \%( \pm 17.82)$ and $90.74 \%( \pm 12.47)$, respectively. The foodsources were: black beans, raw beets, boiled egg, beef, chicken breast and thigh meat. Conclusions: We conclude with present study that iron offer was inadequate only 1-3 years children, in the morning. Lunch was most iron rich meal.

Keywords: Anemia; Anemia Iron-Deficiency; Iron; Child Preschool; Public Health.

\section{INTRODUÇÃO}

A anemia ferropriva é a mais prevalente das carências nutricionais, com maior prevalência em mulheres e crianças, principalmente nos países emergentes ${ }^{1}$. Além disso, é considerada um importante problema de Saúde Pública, que pode levar à fadiga, prejuízo no crescimento, no desenvolvimento neurológico e desempenho escolar, além de distúrbios comportamentais².

Segundo a Organização Mundial da Saúde (OMS), em 2011, a média da prevalência de anemia na região da América Latina e Caribe, a qual incluiu o Brasil, foi de $29,1 \%$ (IC 95\%; 22,5\%-36,9\%) para crianças de 6 a 59 meses de idade. Para a mesma população e período, a prevalência de anemia severa foi de 0,3\% (IC 95\%; 0,2\%$0,7 \%$ ), o que corresponde a cerca de 200.000 crianças $^{3}$. Nesse contexto, as avaliações do consumo alimentar são valiosas para identificar a participação dos nutrientes na dieta e estimar a sua adequação frente aos padrões de referência 4 .

No ano de 2001, antes do uso de alimentos fortificados, um estudo transversal realizado em várias regiões da cidade de São Paulo ${ }^{5}$ analisou a prevalência de anemia em 330 pré-escolares frequentadores de creches da rede municipal, e encontrou uma prevalência de $69 \%$ de anemia nesse grupo. Em revisão da literatura, Jordão, Bernardi e Barros Filho ${ }^{6}$ encontraram dados medianos de prevalência de anemia em 53\% dos pré-escolares brasileiros avaliados nos estudos. Ainda segundo os autores, no território nacional, as regiões que se destacaram pela maior prevalência da anemia foram a Norte e a Centro-Oeste.

Pesquisas mais recentes, após a utilização de alimentos fortificados, revelaram uma prevalência de $21 \%$ de anemia em pré-escolares da região de São Paulo ${ }^{7}$, e de $25,6 \%$ em crianças do Rio de Janeiro ${ }^{8}$, sendo que o maior valor (36\%) foi entre as crianças de 60 a 65 meses de idade. 
Cabe salientar que o ferro proveniente da dieta, na maioria das vezes, é de baixa biodisponibilidade (cereais e leguminosas). Tal característica, associada à introdução do leite de vaca in natura e sua manutenção prolongada com uma menor oferta de outros alimentos, é um fator que propicia a instalação da anemia ferropriva já nos primeiros anos de vida ${ }^{9}$.

Segundo a Resolução ํㅜ 26, de 17 de junho de 2013, do Fundo Nacional de Desenvolvimento da Educação $(F N D E)^{10}$, que dispõe sobre 0 atendimento da alimentação escolar aos alunos da educação básica no Programa Nacional de Alimentação Escolar (PNAE), quando se ofertam duas ou mais refeições no ambiente escolar, elas devem atingir, no mínimo, 30\% das necessidades nutricionais da criança informações essas referentes aos períodos parciais. O aluno que fica na escola em período integral precisa receber, no mínimo, 70\% das necessidades nutricionais previstas. Essa mesma legislação estabelece que é competência do nutricionista responsável técnico o planejamento, a elaboração, o acompanhamento e a avaliação do cardápio de acordo com a cultura alimentar, perfil epidemiológico da referida população, com vistas a promover também ações de educação alimentar e nutricional, a fim de manter os alunos nutricionalmente saudáveis ${ }^{10}$.

Dentro dessa perspectiva, esta pesquisa tem como objetivo avaliar a oferta de ferro para pré-escolares pela análise do cardápio de um centro de educação infantil (CEI) de um município de Santa Catarina, comparando com os valores preconizados pelo PNAE, que tem como base a Referência da Ingestão Dietética (DRI) / Instituto de Medicina Americano (IOM) ${ }^{10}$.

\section{MÉTODOS}

Foi realizado um estudo observacional, transversal, descritivo, prospectivo, de abordagem quantitativa, aprovado pelo Comitê de Ética da Universidade do Extremo Sul Catarinense, conforme parecer ํㅜ 408.735/2013.

A coleta de dados só foi iniciada após ser assinado o Termo de Consentimento Livre e Esclarecido e de Confidencialidade pelo nutricionista responsável técnico.

Foram analisados os cardápios ofertados num CEI, localizado num município do extremo sul de Santa Catarina, para pré-escolares com idade de 1 a 5 anos, no mês de setembro de 2013. Avaliaram-se, no total, 25 refeições, que correspondem a uma 
Artigo Original

Atenção à Saúde

semana de cardápio, considerando 5 refeições diárias. Esse é o mesmo ofertado aos outros centros de educação infantil que não são mantidos pela secretaria de educação do município considerado. A alimentação da escola escolhida está sob a responsabilidade de nutricionistas de uma empresa privada do município.

Para a coleta de dados, utilizou-se um roteiro elaborado pelos autores desta pesquisa, para registro dos alimentos e das quantidades de micronutrientes. $O$ roteiro foi preenchido após recebimento do cardápio semanal que apresentou quantidade em gramas de porção suficiente para uma criança, sendo esta multiplicada pelo respectivo total de alunos que seriam servidos no dia.

A variável dependente representou a quantidade de ferro nas refeições. As independentes foram: alimentos oferecidos em cada refeição do cardápio, recomendação nutricional do PNAE e adequação à resolução vigente do PNAE, que institui oferta de $2,1 \mathrm{mg}$ e $3,0 \mathrm{mg}$ de ferro ao dia, correspondendo a $30 \%$ da recomendado para crianças de 1 a 3 anos e de 4 a 5 anos, respectivamente; e 4,9mg e 7,0mg de ferro ao dia, que equivale a $70 \%$ da recomendação para as mesmas respectivas faixas etárias supracitadas.

Após a coleta de dados, foi elaborado um banco de dados no software Microsoft Excel versão 2012 e foram construídas tabelas e quadro para melhor organização e apresentação dos dados. A composição nutricional dos alimentos foi analisada conforme a Tabela Brasileira de Composição de Alimentos ${ }^{11}$.

Para verificar a presença de alimentos fontes de ferro no cardápio foi considerado fonte de ferro heme: ovo, carne de frango, carne bovina, miúdos e vísceras. Como fonte de ferro não-heme considerou-se os vegetais de cor verde escura ou arroxeados (ex.: beterraba) e leguminosas secas (ex.:feijão) ${ }^{12,13}$.

Após a elaboração do banco de dados, realizou-se a análise estatística no software Statistical Package for the Social Sciences (SPSS) versão 20, sendo calculadas algumas medidas descritivas como média e desvio padrão para as variáveis quantitativas, frequência absoluta e relativa para as qualitativas.

\section{RESULTADOS}

O cardápio recebido para análise fora destinado a crianças de 1 a 5 anos. Observou-se que o cardápio era semanal, sendo repetido pelas outras 3 semanas 
restantes do mês, para todas as faixas etárias, com exceção do berçário. O cardápio semanal foi composto por 32 alimentos diferentes.

O CEI avaliado funcionava em período integral, no entanto, os educandos poderiam optar por frequentar um dos turnos: matutino ou vespertino. Foram oferecidas cinco refeições: desjejum, lanche da manhã, almoço, lanche da tarde e jantar. Quem frequentava apenas o período matutino recebia desjejum, lanche da manhã e almoço. Os pré-escolares que frequentavam apenas durante a tarde recebiam lanche da tarde e jantar. Quem permanecia em período integral, recebia as cinco refeições.

A recomendação de ferro para quem faz mais de uma refeição em período parcial (matutino ou vespertino) é diferente por faixa etária: de 1 a 3 anos e de 4 a 5 anos $^{10}$. No entanto, a quantidade ofertada no cardápio avaliado neste estudo foi similar para ambas as faixas.

As crianças de 1 a 3 anos que frequentaram O CEI no período matutino receberam quantidade de ferro superior à recomendação do PNAE, com percentual de adequação médio de $205,81 \%( \pm 27,32)$, assegurando as quantidades necessárias recomendadas em todos os dias da semana nesse período, conforme demonstrado na Tabela 1. Na faixa etária dos 4 aos 5 anos (Tabela 2), no turno da manhã, também foi atingida a recomendação diária, com média de adequação de $144,07 \%( \pm 19,13)$, garantindo o aporte de ferro preconizado.

Para os alunos do período vespertino, houve déficit do percentual de adequação em alguns dias da semana para os pré-escolares de 1 a 3 anos (Tabela 1), fechando uma média semanal de $96,67 \%( \pm 31,26)$ de adequação à recomendação do PNAE; e, para as crianças de 4 a 5 anos (Tabela 2), em todos os dias a oferta de ferro foi menor que a recomendação, chegando ao percentual médio de adequação de $67,67 \%( \pm 21,88)$. 
Tabela 1. Quantidade de ferro ofertada por refeição para pré-escolares de 1 a 3 anos.

\begin{tabular}{cccc}
\hline & \multicolumn{3}{c}{$\begin{array}{c}\text { Oferta média de } \\
\text { Ferro }(\mathbf{m g})\end{array}$} \\
\cline { 2 - 4 } & QO(DP) & QR & A(DP) \\
\hline Manhã & $4,32(0,57)$ & 2,10 & $205,81(27,32)$ \\
Tarde & $2,03(0,66)$ & 2,10 & $96,67(31,26)$ \\
Integral & $6,35(0,87)$ & 4,90 & $129,63(17,82)$ \\
\hline
\end{tabular}

Fonte: Próprio Autor

\section{Notas:}

$A$ = percentual de adequação ao consumo preconizado pelo Programa Nacional de Alimentação Escolar DP = Desvio Padrão

$\mathrm{QO}=$ quantidade de Ferro $(\mathrm{mg})$ ofertada

$\mathrm{QR}=$ quantidade de Ferro $(\mathrm{mg})$ recomendada pelo Programa Nacional de Alimentação Escolar mg: miligramas

Avaliando a faixa etária de 1 a 3 anos, que recebeu alimentação em período integral no $\mathrm{CEI}$, esta atingiu a recomendação de $70 \%$ da necessidade diária de ferro específica durante a semana, com média de $129,63 \%( \pm 17,82)$ de adequação (Tabela 1). Já para os pré-escolares de 4 a 5 anos (Tabela 2), a quantidade ficou no limite mínimo recomendado, fechando uma média semanal de $90,74 \%( \pm 12,47)$.

Tabela 2. Quantidade de ferro ofertada por refeição para pré-escolares de 4 a 5 anos.

\begin{tabular}{cccc}
\hline & \multicolumn{3}{c}{$\begin{array}{c}\text { Oferta média de } \\
\text { Ferro }(\mathbf{m g})\end{array}$} \\
\cline { 2 - 4 } & $\mathrm{QO}(\mathrm{DP})$ & $\mathrm{QR}(\mathrm{DP})$ & $\mathrm{A}(\mathrm{DP})$ \\
\hline Manhã & $4,32(0,57)$ & $3,00(0)$ & $144,07(19,13)$ \\
Tarde & $2,03(0,66)$ & $3,00(0)$ & $67,67(21,88)$ \\
Integral & $6,35(0,87)$ & $7,00(0)$ & $90,74(12,47)$ \\
\hline
\end{tabular}

Fonte: Próprio Autor

\section{Notas:}

$A$ = percentual de adequação ao consumo preconizado pelo Programa Nacional de Alimentação Escolar $\mathrm{DP}=$ Desvio Padrão

$\mathrm{QO}=$ quantidade de Ferro $(\mathrm{mg})$ ofertada 
$\mathrm{QR}=$ quantidade de Ferro $(\mathrm{mg})$ recomendada pelo Programa Nacional de Alimentação Escolar mg: miligramas

No Quadro 1 se encontram descritos os alimentos fontes de ferro encontrados no cardápio, os quais foram: feijão preto, servido todos os dias, no almoço, e duas vezes na semana, no jantar; beterraba crua, uma vez na semana, no almoço; ovo cozido, uma vez na semana, no almoço; carne bovina, duas vezes na semana, no almoço; bolo simples (devido aos ovos), duas vezes na semana, no lanche da tarde; peito de frango, duas vezes na semana, uma no almoço, uma no jantar; coxa de frango, uma vez na semana, no almoço. Desses, apenas a carne bovina, a coxa de frango e o bolo simples (devido aos ovos e à farinha de trigo enriquecida com ferro) foram os que atingiram $1 \mathrm{mg}$ de Ferro na porção, os demais apresentaram quantidades inferiores a 0,01 mg de Ferro.

Quadro 1. Alimentos fontes de ferro presentes no cardápio de pré-escolares.

\begin{tabular}{|c|c|c|}
\hline $\begin{array}{c}\text { Dia da semana } \\
\text { Refeição }\end{array}$ & Alimento & Tipo de ferro ofertado \\
\hline $\begin{array}{l}\text { Segunda-feira } \\
\text { Desjejum } \\
\text { Lanche da Manhã } \\
\text { Almoço } \\
\text { Lanche da Tarde } \\
\text { Jantar }\end{array}$ & $\begin{array}{l}\text { NA } \\
\text { NA } \\
\text { Feijão preto }^{1} \\
\text { Beterraba (crua) }^{1} \\
\text { Ovo cozido }^{1} \\
\text { Bolo simples } \\
\text { NA }\end{array}$ & $\begin{array}{l}\text { NA } \\
\text { NA } \\
\text { Ferro não-heme } \\
\text { Ferro não-heme } \\
\text { Ferro heme } \\
\text { Ferro heme } \\
\text { NA } \\
\end{array}$ \\
\hline $\begin{array}{l}\text { Terça-feira } \\
\text { Desjejum } \\
\text { Lanche da Manhã } \\
\text { Almoço } \\
\text { Lanche da Tarde } \\
\text { Jantar }\end{array}$ & $\begin{array}{l}\text { NA } \\
\text { NA } \\
\text { Carne Bovina } \\
\text { Feijão preto }{ }^{1} \\
\text { NA } \\
\text { Feijão preto }{ }^{1}\end{array}$ & $\begin{array}{l}\text { NA } \\
\text { NA } \\
\text { Ferro heme } \\
\text { Ferro não-heme } \\
\text { NA } \\
\text { Ferro não-heme } \\
\end{array}$ \\
\hline $\begin{array}{l}\text { Quarta-feira } \\
\text { Desjejum } \\
\text { Lanche da Manhã } \\
\text { Almoço } \\
\text { Lanche da Tarde } \\
\text { Jantar }\end{array}$ & $\begin{array}{l}\text { NA } \\
\text { NA } \\
\text { Feijão preto }{ }^{1} \\
\text { Peito de Frango }{ }^{1} \\
\text { Bolo simples } \\
\text { NA }\end{array}$ & $\begin{array}{l}\text { NA } \\
\text { NA } \\
\text { Ferro não-heme } \\
\text { Ferro heme } \\
\text { Ferro heme } \\
\text { NA }\end{array}$ \\
\hline $\begin{array}{l}\text { Quinta-feira } \\
\text { Desjejum } \\
\text { Lanche da Manhã } \\
\text { Almoço } \\
\text { Lanche da Tarde }\end{array}$ & $\begin{array}{l}\text { NA } \\
\text { NA } \\
\text { Feijão preto }{ }^{1} \\
\text { Carne bovina } \\
\text { NA }\end{array}$ & $\begin{array}{l}\text { NA } \\
\text { NA } \\
\text { Ferro não-heme } \\
\text { Ferro heme } \\
\text { NA }\end{array}$ \\
\hline
\end{tabular}


Artigo Original

Atenção à Saúde

\begin{tabular}{|l|l|l|}
\hline Jantar & Feijão preto $^{1}$ & Ferro não-heme \\
\hline Sexta-feira & & \\
Desjejum & NA & NA \\
Lanche da Manhã & NA & NA \\
Almoço & Feijão preto ${ }^{1}$ & Ferro não-heme \\
& Coxa de frango & Ferro heme \\
Lanche da Tarde & NA & NA \\
Jantar & Peito de frango ${ }^{1}$ & Ferro heme \\
\hline
\end{tabular}

Fonte: Próprio Autor

Notas:

$\mathrm{NA}=$ Não Apresentou

${ }^{1}$ Não atingiu $1 \mathrm{mg}$ de ferro na porção ofertada

${ }^{2}$ Ferro proveniente dos ovos da massa e farinha de trigo enriquecida com ferro

\section{DISCUSSÃO}

A deficiência de ferro é tida como a carência nutricional de maior prevalência em todo o mundo, e afeta principalmente lactentes, pré-escolares, adolescentes e gestantes. Mesmo na ausência de anemia, a simples insuficiência de ferro pode carrear distúrbios neurocognitivos ${ }^{14}$. Ela é causada quase que exclusivamente por má alimentação, com o fornecimento de alimentos inadequados e excesso de leite de vaca não modificado. A evidência para um efeito de deficiência de ferro no desenvolvimento neurológico não é absoluta, mas é suficientemente convincente para fazer da triagem ou suplementação rotinas necessárias no futuro ${ }^{15}$.

Nosso estudo sugere que o fato de os alunos do período da manhã receberem três refeições e os que frequentam o período vespertino receberem apenas duas refeições pode contribuir para as discrepâncias dos valores apresentados para os períodos parciais nos resultados. Entretanto, não extingue o fato de que a recomendação preconizada pelo PNAE continua a mesma para ambas as situações, devendo o CEI atendê-la, mesmo com quantidades de refeições diferentes. Assim, é importante conhecer quanto se tem de ferro nos alimentos para fazer um balanço nutricional adequado nas refeições, atentando para os alimentos fontes ${ }^{12,13}$.

É relevante citar que os alimentos fontes de ferro heme e não-heme encontrados no cardápio foram predominantemente ofertados no almoço, uma refeição que não foi proporcionada a todos os alunos. Adiciona-se a isso o fato de que mesmo esses alimentos sendo presentes no cardápio, a quantidade de ferro ofertada pelos mesmos, em algumas situações, foi muito pequena. 
Existe uma diferença dessas fontes de ferro em relação à biodisponibilidade desse mineral. $\mathrm{O}$ ferro heme contido nas carnes e produtos de origem animal é mais biodisponível que o ferro não-heme, sendo, por exemplo, encontrado em alimentos de origem vegetal ${ }^{12}$. Normalmente, o ferro não-heme é encontrado em vegetais verdesescuros como agrião, espinafre, entre outros ${ }^{13}$.

É importante destacar que as crianças de 1 a 3 anos devem ingerir $7 \mathrm{mg}$ de ferro por dia, enquanto crianças de 4 a 8 anos precisam de $10 \mathrm{mg}$ diárias de ferro para suprir sua necessidade desse mineral no organismo ${ }^{16}$. Sendo assim, num cardápio onde uma mesma quantidade de alimentos é ofertada a ambas as faixas etárias, é interessante elaborar estratégias para adequar a oferta, que pode ser nivelar o cálculo pelo valor mais alto (10mg) da recomendação e, assim, garantir o aporte adequado a todos, ou, ainda, oferecer medidas de porções diferentes conforme a idade, adequando também às necessidades nutricionais.

De acordo com as recomendações da $\mathrm{OMS}^{17}$ para suplementação de ferro em crianças com idade pré-escolar e escolar, quando a prevalência de anemia nesse público é maior ou igual a $20 \%$, em cuja categoria se enquadra o Brasil de acordo com os dados supracitados, é fortemente recomendada a suplementação intermitente de ferro como intervenção de saúde pública para melhorar o estado nutricional do ferro e reduzir o risco de anemia entre as crianças ${ }^{17}$.

Num estudo realizado no ano de $2007^{18}$, em que 240 alunos da quarta série de 10 escolas municipais de João Pessoa, Paraíba, beneficiários do PNAE, foram questionados sobre a alimentação escolar, os resultados mostraram que $0,9 \%$ referiram só frequentar a escola pela oferta da merenda e 4,4\% deixariam de frequentá-la, caso 0 PNAE fosse extinto. A inadequação ao hábito alimentar e o sabor foram os principais motivos referidos pelas crianças para não aderir e aceitar a alimentação, respectivamente. A adequação do cardápio aos hábitos alimentares e à essencialidade do PNAE para reduzir a evasão escolar são fatores que requerem maior investigação. Apesar de não ter sido abordado em nosso estudo, esse assunto é relevante, pois corrobora para a compreensão dos motivos que também interferem no cardápio escolar, como, por exemplo, a aceitabilidade.

Uma revisão sistemática conduzida pela Cochrane, que incluiu 33 ensaios clínicos randomizados, envolvendo 13.144 crianças de 20 países (América Latina, África e Ásia) nos quais a prevalência de anemia varia de moderada a alta, mostrou que a 
Artigo Original

Atenção à Saúde

suplementação de ferro intermitente reduz, no intervalo médio de um ano, a deficiência de ferro em $51 \%$ e a anemia em $31 \%$ quando comparadas às crianças que receberam placebo ou não receberam nenhuma suplementação ${ }^{19}$.

Um outro estudo ${ }^{20}$ que avaliou a alimentação escolar oferecida aos alunos do ensino fundamental de dezesseis escolas municipais de Lavras, MG, mostrou que a meta de fornecer $15 \%$ das necessidades nutricionais dos alunos na alimentação escolar das unidades de ensino municipal, no ano de 2004, não foi totalmente atingida, pois a maioria das adequações nutricionais ficou fora da faixa recomendada. Contudo, as metas de oferta de proteína e ferro foram atendidas por todas as escolas, ficando acima do preconizado pelo PNAE. Diferente de nossa pesquisa, os resultados supracitados encontraram deficiências de outros micronutrientes da alimentação escolar, embora a quantidade de ferro estivesse adequada.

Resultados de uma revisão sistemática com meta-análise, que avaliou trabalhos publicados no período de 1966 a 2006, revelaram que os programas de alimentação escolar têm pequenos efeitos na antropometria de escolares, particularmente em contextos de baixa renda ${ }^{21}$. As expectativas dos maiores efeitos são na altura dos escolares, ganho de peso positivo em populações abaixo do peso ou negativo quando há grande risco de obesidade. Em países de renda média, a alimentação escolar pode servir como oportunidade para combater a obesidade. O Brasil e o Chile redesenharam seus programas considerando este fator de risco ${ }^{22}$. As inadequações referentes ao cardápio da alimentação escolar encontradas em nosso estudo podem contribuir para a não existência dos efeitos positivos na antropometria e no perfil socioeconômico das famílias destes pré-escolares.

A alimentação escolar também pode beneficiar outros membros da família quando a ingestão da criança em idade escolar em casa é reduzida ${ }^{23,24}$. Em nosso estudo, o CEI avaliado pertence a uma área de vulnerabilidade social, sendo assim a alimentação escolar pode ter forte contribuição na alimentação das famílias e nos gastos das mesmas com alimentos.

Ensaios randomizados controlados realizados em Burkina Faso e Uganda ${ }^{25}$ mostraram efeitos sobre o peso entre meninos em idade pré-escolar, ou seja, menores de cinco anos, cujos irmãos receberam alimentação escolar ou rações para levar para casa, em comparação com um grupo controle. Tal questão corrobora o fato de que a 


\section{Atenção à Saúde}

inadequação do cardápio escolar pode interferir na realidade socioeconômico-educativa dos pré-escolares, como supracitado.

Já uma revisão narrativa ${ }^{24}$ de avaliações aleatórias de alimentação escolar rica em ferro (fortificada ou fornecendo alimentos de origem animal) documentou que três de quatro estudos mostraram melhoria do estado nutricional do ferro, independente do seu estado inicial. A adição à alimentação escolar da Índia de uma mistura em sachês, rica em micronutrientes, lançada pelo United Nations Children's Fund (UNICEF), melhorou o ferro total do organismo, mas não a anemia, possivelmente, segundo os autores, por causa de grande quantidade de vermes ${ }^{26}$. Dessa forma, pode-se ratificar a importância da adequação da oferta de ferro na alimentação escolar não apenas para cumprimento das recomendações do PNAE, mas para a melhoria do estado nutricional do ferro e da situação de saúde dessas crianças.

Para identificar o estado nutricional do ferro (ENF), um levantamento bibliográfico feito nas bases de dados Medline, Lilacs e Dedalus, que selecionou publicações científicas em português e inglês de 1972 a 1998, buscou reunir informações a respeito dos parâmetros disponíveis para avaliar o ENF em indivíduos e populações, e concluiu que a avaliação da deficiência de ferro no organismo é melhor realizada quando combinados vários parâmetros hematológicos e bioquímicos. Quando não for possível, a alternativa é o uso isolado da dosagem de hemoglobina. Afirmam ainda que não existe parâmetro ou combinação ótimos para o diagnóstico do ENF ${ }^{14}$.

Uma das maneiras que o governo encontrou de suplementar o ferro foi adicionando-o a alguns tipos de alimentos, como as farinhas de trigo e de milho. A respeito disso, há que se considerar as publicações atuais ${ }^{7}$ que revelam um aumento médio, estatisticamente significativo, na concentração de ferro total dos cardápios, de 31 e $41 \%$ para as crianças de 24 a 47 e 48 a 60 meses de idade, respectivamente. Confirmam, também, a redução da prevalência de anemia nos pré-escolares devido a essa fortificação $0^{5,7}$.

Mais recentemente, com o apoio técnico do UNICEF, o Ministério da Saúde lançou um projeto-piloto para utilização de Micronutrientes em Pó (MNPs) no combate à anemia ferropriva em crianças ${ }^{27}$. Tal projeto tem o objetivo de apurar os resultados das suplementações de alguns micronutrientes, ofertando um sachê com as doses recomendadas diárias, que será adicionado ao prato da criança na hora da refeição. 


\section{Atenção à Saúde}

Essa medida poderá contribuir e facilitar a adequação do cardápio nas escolas em geral $^{27}$.

No Brasil, o governo confirmou, no ano de 2012, que adotara a administração dos MNPs para 2.700 creches brasileiras. O produto, desenvolvido pela Universidade de Toronto, contém 15 micronutrientes na sua composição: Ferro (10mg), Zinco (4,1mg),

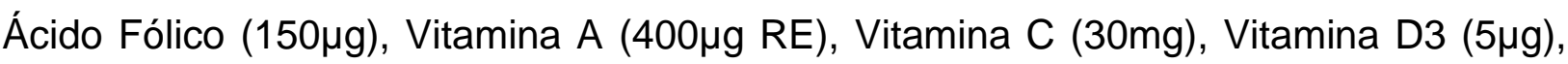
Vitamina E (6mg TE), Vitamina B1 (0,5mg), Vitamina B2 (0,5mg), Vitamina B6 (0,5mg), Vitamina B12 $(0,9 \mu \mathrm{g})$, Niacina $(6 \mathrm{mg})$, Cobre $(0,56 \mathrm{mg})$, lodo $(90 \mu \mathrm{g})$, Selênio $(17 \mu \mathrm{g})^{28}$.

Segundo o UNICEF, é uma terapia mais completa que a administração via oral de ferro, de fácil aceitação e utilização pelas famílias pobres, que combaterão, além da anemia ferropriva, a desnutrição também. Os MNPs serão distribuídos gratuitamente pelo Ministério da Saúde do Brasil. De acordo com dados da Coordenação Geral de Alimentação e Nutrição (CGAN), este produto esteve em estudo por cinco universidades brasileiras (USP, UFG, UFPE, UFAC e UFCSPA), avaliando o efeito do mesmo sob dois tipos de cuidados ofertados no país na Atenção Básica: Tradicional e Estratégia de Saúde da Família. O estudo avaliou o efeito da estratégia de fortificação caseira no Brasil $^{29}$.

Oficialmente, no mês de março de 2015, o Ministério da Saúde do Brasil lançou o NutriSUS, que é a estratégia de fortificação da alimentação infantil com MNPs, adicionando-os diretamente à refeição oferecida nas creches às crianças com idade entre 6 meses a 3 anos e 11 meses de vida ${ }^{30}$.

Outra pesquisa publicada em $2013^{31}$ rematou que as diretrizes e os princípios do PNAE mostram que sua execução é complexa e que extrapola o entendimento usual de que o Programa serve apenas para fornecer alimentação saudável às crianças. Como apresentado neste estudo, as recompensas de se adequar ao PNAE vão além da alimentação saudável. Neste caso, há uma preocupação com a adequação da quantidade ofertada de ferro, que como mostram os resultados de nosso estudo, não se atendeu, em partes, às recomendações. Em se tratando de consumo de ferro, cabe atentar que este nutriente está diretamente ligado ao estado nutricional, anemias e carências nutricionais ${ }^{24}$.

Mediante os resultados apresentados pela análise do cardápio, é possível concluir que a quantidade de ferro ofertada adequou-se ao recomendado pelo PNAE apenas para as crianças de 1 a 3 anos, deixando a desejar na quantidade oferecida para 
Artigo Original

Atenção à Saúde

estudantes de 4 a 5 anos. O mesmo se concluiu quanto aos turnos: a alimentação escolar apresentou percentuais de adequação decrescentes nos períodos matutino, integral e vespertino, respectivamente.

Entende-se que existe a necessidade de porções diferentes respeitando as faixas etárias, porquanto se percebeu que uma mesma porção para ambas as faixas etárias não supriu as necessidades diárias de ferro de todas as crianças ${ }^{10}$.

O almoço foi a refeição mais rica em ferro nesse cardápio. No entanto, não era ofertado a todas as crianças. Isso interferiu, também, na adequação da alimentação dos períodos vespertino e integral. Uma forma de amenizar essa questão é ofertar o almoço a todos os estudantes, aumentando consequentemente a oferta e o percentual de adequação.

Contudo, nosso estudo se ateve à quantidade de ferro ofertada e ao percentual de adequação. Incentiva-se a realização de estudos subsequentes que verifiquem o que realmente é consumido e qual a correlação da alimentação escolar e a prevalência de anemia nos estudantes, estado nutricional do ferro, entre outros.

\section{REFERÊNCIAS}

1. Heijblom GS, Santos LMP. Anemia ferropriva em escolares da primeira série do ensino fundamental da rede pública de educação de uma região de Brasília, DF. Rev Bras Epidemiol 2007;10(2):258-266.

2. Carvalho MC, Baracat ECE, Sgarbieri VC. Anemia ferropriva e anemia de doença crônica: distúrbios do metabolismo do ferro. SAN 2006;13(2):54-63.

3. WHO. The global prevalence of anaemia in 2011. Geneva: World Health Organization; 2015.

4. Costa EC, Silva SP O, Lucena JRM, Batista Filho M, Lira PIC, Ribeiro M A. Consumo alimentar de crianças em municípios de baixo índice de desenvolvimento humano no Nordeste do Brasil. Rev Nutr 2011;24(3):395-405.

5. Bueno MB, Selem SSC, Arêas JAG, Fisberg RM. Prevalência e fatores associados à anemia entre crianças atendidas em creches públicas de São Paulo. Rev Bras Epidemiol $2006 ; 9(4): 462-70$.

6. Jordao RE, Bernardi JLD, Barros Filho AA. Prevalência de anemia ferropriva no Brasil: uma revisão sistemática. Rev Paul Pediatr 2009;27(1):90-98. 
7. Costa CA, Machado EH, Colli C, Latorre WC, Szarfarc SC. Anemia in pre-school children attending day care centers of São Paulo: perspectives of the wheat and maize flour fortification. Nutrire: J Brazilian Soc Food Nutr 2009;34(1):59-74.

8. Costa JT, Bracco MM, Gomes PA, Gurgel RQ. Prevalence of anemia among preschoolers and response to iron supplementation. J Pediatr (Rio J) 2011;87(1):76-79.

9. Braga JAP, Vitalle MSS. Deficiência de ferro na criança. Rev Bras Hematol Hemoter 2010;32 (Suppl 2):38-44.

10. Brasil. Poder Legislativo. Resolução oㅡ 26, de 17 de junho de 2013. Dispõe sobre o atendimento da alimentação escolar aos alunos da educação básica no âmbito do Programa Nacional de Alimentação Escolar - PNAE. Diário Oficial da União 2013; 18 jun

11. Núcleo de Estudos e Pesquisas em Alimentação. Tabela brasileira de composição de alimentos. 4 ed. Campinas: UNICAMP; 2011.

12. Brigide P. Disponibilidade de ferro em grãos de feijão comum (Phaseolusvulgaris L.) irradiados [Dissertação]. Piracicaba: USP; 2002.

13. Queiroz SS, Torres MA. Anemia ferropriva na infância. J Pediatr (Rio J). 2000;76:298304.

14. Paiva AA, Rondó PHC, Guerra-Shinohara EM. Parâmetros para avaliação do estado nutricional de ferro. Rev Saúde Pública 2000;34(4):421-426.

15. Harris RJ, Iron deficiency anaemia: does it really matter? Paediatr Child Health 2007;17(4):143-146.

16. Institute of Medicine. National Academy of Sciences. Dietary reference intakes for vitamin $\mathrm{A}$, vitamin $\mathrm{K}$, arsenic, boron, chromium, copper, iodine, iron, manganese, molybdenum, nickel, silicon, vanadium, and zinc. Washington, D.C.: National Academy Press 2001;65-126.

17. Guideline: Intermittent iron supplementation in preschool and school-age children. Geneva: World Health 2011 (http://apps.who.int/iris/bitstream/10665/44648/1/9789241502009_eng.pdf?ua=1)

18. Muniz VM, Carvalho AT. National School Feeding Program in municipality of Paraíba state: a study under the viewpoint of those who benefit from the program. Rev Nutr 2007;20(3):285-296.

19. De-Regil LM et al. Intermittent iron supplementation for improving nutrition and developmental outcomes in children under 12 years of age. Cochrane Database of Systematic Reviews, 2011(12):CD009085 (http://onlinelibrary.wiley.com/doi/10.1002/14651858.CD009085.pub2/abstract). 
20. Flávio EF, Barcelos MFP, Cirillo MA, Ribeiro AH. Avaliação da alimentação escolar oferecida aos alunos do ensino fundamental das escolas municipais de Lavras, MG. Ciênc Agrotec 2008;32(6):1879-87.

21. Kristjansson B, Robinson V, Petticrew M, MacDonald B, Krasevec J, Janzen L, et al. School feeding for improving the physical and psychosocial health of disadvantaged elementary school children. Cochrane Database Syst Rev 2007;1:CD004676.

22. Doak C. Large-scale interventions and programmes addressing nutrition related chronic diseases and obesity: examples from 14 countries. Public Health Nutr 2002;5:275-77.

23. Afridi F. Child welfare programs and child nutrition: evidence from a mandated school meal program in India. J Dev Econ 2010;92:152-65.

24. Adelman S, Gilligan DO, Lehrer K. How effective are food for education programs? A critical assessment of the evidence from developing countries. Washington (DC): International Food Policy Research Institute; 2008.

25. Kazianga $\mathrm{H}$, De Walque $\mathrm{D}$, Alderman $\mathrm{H}$. Educational and health impact of two school feeding schemes: evidence from a randomized trial in rural Burkina Faso. Washington (DC): World Bank; 2009.

26. Osei AK, Rosenberg IH, Houser RF, Bulusu S, Mathews M, Hamer DH. Community level micronutrient fortification of school lunch meals improved vitamin $A$, folate, and iron status of schoolchildren in Himalayan villages of India. J Nutr 2010;140:1146-54.

27. Unicef. Relatorio Anual 2012. Brasília (DF): UNICEF; 2013:9(26).

28. Unicef. Uni. Boletim informativo do Unicef Brasil. Brasília (DF): UNICEF; 2012:8(24).

29. Brasil. Ministério da Saúde. Secretaria de Atenção à Saúde. Departamento de Atenção Básica. Estratégia de Fortificação Caseira no Brasil: Workshop 29 e 30 de setembro de 2011; 2012.

30. Brasil. Ministério da Saúde. NutriSUS - Estratégia de fortificação da alimentação infantil com micronutrientes (vitaminas e minerais) em pó : manual operacional / Ministério da Saúde, Ministério da Educação. - Brasília : Ministério da Saúde, 2015. $52 \mathrm{p}$.

31. Chaves LG, Santana TCM, Gabriel CG, Vasconcelos FAG. Reflexões sobre a atuação do nutricionista no Programa Nacional de Alimentação Escolar no Brasil. Ciênc Saúde Coletiva. 2013;18(4):917-926. 